\title{
Evaluation of the Hazard of Fire Resistant Materials Using Measurements from Laboratory and Parallel Panel Tests
}

\author{
Ronald L. Alpert \\ FM Global Research \\ Norwood, MA 02062-9102, USA
}

\begin{abstract}
This paper describes new concepts for evaluating the fire propagation hazard of exposed polymer materials exhibiting low heat release rates (typically less than $200 \mathrm{~kW} / \mathrm{m}^{2}$ ). While the intent of most fire propagation models is to predict details such as the position of flame or pyrolysis fronts as a function of time in a room-corner scenario, engineers often simply need to know whether a material will support sustained fire propagation or not. To accomplish this objective, a 2.4-m high parallel panel configuration is studied as a reference scenario for determining fire propagation behavior apart from other complicating factors, such as flashover potential or excess pyrolyzate production. Coupled to this test configuration is laboratory analysis of the polymer that provides quantitative information on two key parameters for a simplified predictive model of fire behavior: 1) the ratio of the heat of combustion to the heat of gasification and 2) particulate yield of the polymer flames. Procedures for obtaining these parameters are described for three materials, two nominally identical polyvinychloride polymers of different thickness and a fire-retarded polypropylene. The behavior of these three materials in the parallel panel configuration when exposed to gas burner flames of varying intensity is analyzed and compared to model predictions. Based on the analysis, it is concluded that accurate determination of the heat of gasification in an inert, nitrogen environment is important for understanding the hazard of fire resistant materials.
\end{abstract}

KEYWORDS: fire propagation, flame spread, flammability, parallel panel apparatus

\section{INTRODUCTION}

There is often a need to evaluate the fire propagation hazard of exposed polymer materials exhibiting low heat release rates (typically less than $200 \mathrm{~kW} / \mathrm{m}^{2}$ ). Such materials may be used in high value or sensitive occupancies, where even minimal fire growth cannot be tolerated, or in occupancies where the interior lining of a building must resist substantial exposure flames without any active or passive protection. In these situations, engineers are faced with making timely judgements about exposed plastic materials based on a minimum of information. Problems of this sort could be attacked with any one of a large number of fire propagation models that have been developed over the past decade or so (see Table 1). However, the intent of most fire propagation models is to predict fire growth details, such as the position of flame or pyrolysis fronts as a function of time in a room-corner scenario, and most of the models require a great deal of input information. 
Table 1 Examples of Literature on Fire Propagation Modeling

\begin{tabular}{|c|c|}
\hline Description of Propagation Model & Authors and Date of Work \\
\hline Thermal modeling of upward wall flame & Hasemi [1] \\
spread & 1986 \\
\hline Upward fire spread and growth on single & Delichatsios et al. [2] \\
vertical wall & 1990 \\
\hline $\begin{array}{c}\text { Calculation of flame spread on wall lining } \\
\text { materials in the room-corner test }\end{array}$ & Karlsson [3], [4] \\
\hline Predicting the spread rates of fires on & $1990-1994$ \\
\hline vertical surfaces & Mitler [5] \\
\hline Turbulent upward flame spread for burning & 1990 \\
\hline vertical walls made of finite thickness & Kulkarni et al. [6] \\
\hline Rate of heat release and ignitability indices & 1991 \\
\hline for surface linings & Kokkala et al. [7] \\
\hline Simulation model for fire growth on & 1993 \\
\hline materials subject to a room-corner test & Quintiere et al. [8], [9] \\
\hline Upward flame spread on surface products: & Kokkala et al. [10] \\
experiments \& numerical modeling & 1997 \\
\hline Computer model of upward flame spread & Williams et al. [11] \\
on vertical surfaces & 1997 \\
\hline CFD simulation of upward flame spread \\
over fuel surface & Yan and Holmstedt [12] \\
\hline Numerical simulation of enclosure fires & 1997 \\
using a CFD model coupled with a & Jia et al. [13] \\
pyrolysis- based combustion submodel & 1999 \\
\hline Development of a model for predicting fire & Lattimer et al. [14] \\
growth in a combustible corner & 1999 \\
\hline Modeling burning of large-scale vertical & Wang et al. [15] \\
parallel surfaces with fire-induced flow & 1999 \\
\hline Numerical model of upward flame spread & Brehob et al. [16] \\
on practical wall materials & 2001 \\
\hline & \\
\hline & \\
\hline
\end{tabular}

Engineers, on the other hand, often simply need to be assured that a material will not support sustained fire propagation in a reasonably worst-case situation and this determination must be made as economically as possible. An intermediate-scale reference scenario that contains the essential features of real-scale fire behavior could satisfy this engineering need, especially if results are verified by an easily implemented, predictive model. The 2.4-m high parallel panel configuration is such a reference scenario. One version of this test configuration, shown in Fig. 1, has been in use for several years by P.K. Wu [17] at FM Global Research to qualify materials to be used in semiconductor clean rooms. 


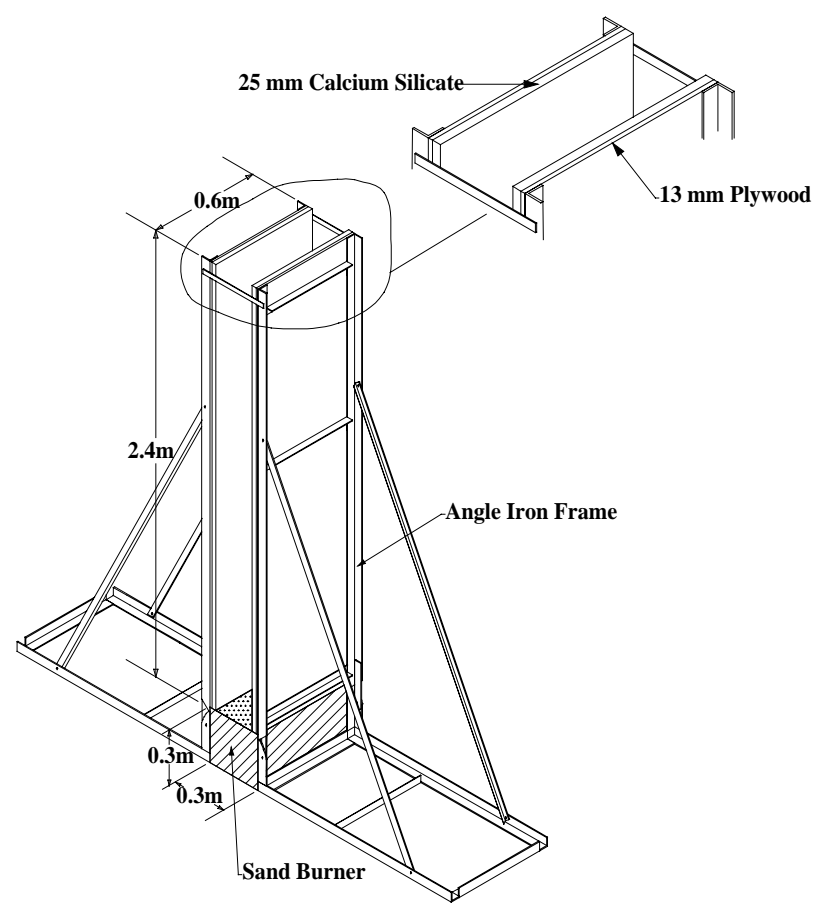

Fig. 1 Parallel Panel Apparatus

\section{THE PARALLEL PANEL APPARATUS}

A parallel panel configuration, in which two panels, each 2.4-m high x 0.6-m wide, are separated by a $0.3-\mathrm{m} \times 0.6-\mathrm{m}$ sand burner, has inherent advantages as a test of material flammability, e.g.:

1. Sufficient size and confinement of flames to yield realistic flame heat transfer (heat fluxes well above $100 \mathrm{~kW} / \mathrm{m}^{2}$ have been measured during propagating fires)

2. Simple geometry to increase the likelihood of modeling success

3. Small area of sample to make the test economical (about 10\% of the specimen area required for typical room-corner test methods)

The confinement of heat resulting from the parallel panel arrangement does not come at the expense of limitations on air access or ventilation for the combustion process due to the particular ratios of panel width to panel separation distance that typically are used. Such limitations have been a particular concern for flammability test methods utilizing a duct or tunnel geometry. Whether sustained fire propagation occurs in the parallel panel configuration is mainly determined by heat transfer feedback from the burner exposure flames combined with flames from the burning panel material itself. 
Depending on the composition of the panel specimen and the heat release rate of the sand burner flame, three types of fire behavior are observed. With some combinations of material and burner intensity, there is virtually no change in heat release rate (measured using a collector hood and instrumented duct above the apparatus) from that of the burner alone. For other combinations, the fire propagates part way up the panels and then stabilizes at a steady heat release rate significantly greater than that of the sand burner. The former solution results in an amplification factor (ratio of heat release rate of the parallel panel materials plus burner to that of the burner alone) of unity while the latter case can yield an amplification factor of two or more. A third type of fire behavior results in a heat release rate that increases rapidly until the entire panel is involved and flames are well above the top of the panels.

\section{APPROACH TO MODELING PARALLEL PANEL FIRE BEHAVIOR}

The following simplifying assumptions are made so that a model of gross fire behavior in the parallel panel apparatus can be developed with a few easily obtained inputs:

1. Details of fire propagation can be ignored, enabling a global energy balance method to determine fire heat release rates consistent with the parallel panel environment.

2. The origin of the fuel vapors is ignored in the simple energy balance.

3. Solid phase pyrolysis behavior is represented by a constant heat of gasification

From conservation of energy, the heat release rate, $\dot{Q}$, that would be measured by a collection hood above a parallel panel apparatus that includes a burner having heat release rate, $\dot{Q}_{b}$, and combustible panels having a heat release rate, $\dot{Q}_{\text {panel }}$, is given by:

$$
\dot{Q}=\dot{Q}_{b}+\dot{Q}_{\text {panel }}
$$

The heat release rate due to the combustible panels is related to the integrated net flame heat transfer, $\dot{Q}_{f}^{\text {net }}$, to the panels by:

$$
\dot{Q}_{\text {panel }}=\frac{\Delta H_{c}}{\Delta H_{g}} \dot{Q}_{f}^{n e t}=\Gamma \dot{Q}_{f}^{n e t}
$$

where,

$$
\dot{Q}_{f}^{n e t}=\iint\left(\dot{q}_{f}^{\prime \prime}-\dot{q}_{o}^{\prime \prime}\right) d A \text { for } \dot{q}_{f}^{\prime \prime} \geq \dot{q}_{o}^{\prime \prime}
$$

The net flame heat transfer in Eq. 3 is obtained by integration over the area, A, of the two panel surfaces to yield the net contribution from the flame heat flux, $\dot{q}_{f}^{\prime \prime}$ and the heat loss flux (which includes mainly reradiation losses), $\dot{q}_{o}^{\prime \prime}$. 
Because of the geometry of the parallel panel configuration, about half of the reradiation flux from one panel becomes an external flux for the opposite panel, instead of being lost to the environment. Hence, reradiation losses are expected to be negligible compared to radiant emission from the flames that fill the space between the panels.

Without additional information, it is assumed that the net, integrated flame heat transfer to the panels is proportional to the total radiant emission from the turbulent flames of sand-burner and panel vapors. In reality, detailed numerical calculations or heat transfer measurements applicable to widely different types of flame sootiness and a specific geometric configuration are needed to determine the functional form of this flame heat transfer to the parallel panels. Although an integrated flame heat transfer directly proportional to total radiant emission is not unreasonable as a first approximation, this assumption disregards some critical physics related to the effect of burner intensity. The expressions in the following analysis, based on data for turbulent jet flames, are thus used to illustrate a general approach, rather than being definitive.

Markstein [18] shows that the radiant fraction, $\chi_{R}$, of heat release rate from a turbulent jet flame is linearly dependent on the smoke point height associated with the burning fuel vapors as follows:

$$
\chi_{R}=0.43-0.91 L_{s}
$$

where $L_{s}[\mathrm{~m}]$ is the minimum height of a laminar flame burning these same fuel vapors for which soot particles exit the flame tip. Since smoke point height is difficult to measure for a solid material, it is convenient to relate this quantity to another parameter that characterizes fuel sootiness, namely the particulate, yield, $\mathrm{y}_{\mathrm{s}}$, from a flame. Using data on six gaseous fuels having smoke point heights ranging from 0.006 to $0.243 \mathrm{~m}$ compiled by Tewarson [19], it is possible to obtain the following correlation (regression coefficient of $0.99+$ ) with corresponding values of particulate yield for these fuels:

$$
L_{s}=0.277 \exp \left\{-22.5 y_{s}\right\}
$$

From Eq. 4 and 5, the total radiant emission from the turbulent flames becomes:

$$
\dot{Q}_{R}=\dot{Q}_{\text {tot }}\left[0.43-0.252 \exp \left\{-22.5 y_{s}\right\}\right]
$$

where $\dot{Q}_{\text {tot }}$ is the heat release rate based on complete combustion of the fuel vapors.

To further simplify the model until further information is available, the proportionality factor between radiant emission in Eq. 6 and net flame heat transfer to the parallel panels, $\dot{Q}_{f}^{\text {net }}$ in Eq. 3 is taken to be unity, which implies that radiant heat loss from the panel flames is being ignored. However, this assumption is partly compensated by also ignoring convective heat transfer to the panels from the turbulent flames. If, in addition, $\dot{Q}_{\text {tot }} \approx \dot{Q}$, Eq. 1 and 2 now become: 


$$
\dot{Q}=\dot{Q}_{b}+\Gamma \dot{Q}\left[0.43-0.252 \exp \left\{-22.5 y_{s}\right\}\right]
$$

The solution of Eq. 7 for the heat release rate measured by a calorimeter above the apparatus is given by:

$$
\dot{Q}=\frac{\dot{Q}_{b}}{1-\Gamma\left[0.43-0.252 \exp \left\{-22.5 y_{s}\right\}\right]}
$$

Note that this solution, based on a global energy balance, does not require detailed spatial information on flame heat transfer but only an integrated result for the panel as a whole.

Equation 8 shows that the heat release rate of the parallel panel system becomes infinite, which is interpreted here as sustained fire propagation, when the following condition is satisfied:

$$
\Gamma\left[0.43-0.252 \exp \left\{-22.5 y_{s}\right\}\right]=1
$$

Critical conditions for fire propagation based on Eq. 9 are shown in Fig. 2, where it is seen that for particulate yields greater than about 0.09 , the value of $\Gamma$ must be greater than about 2.4 to cause sustained fire propagation.

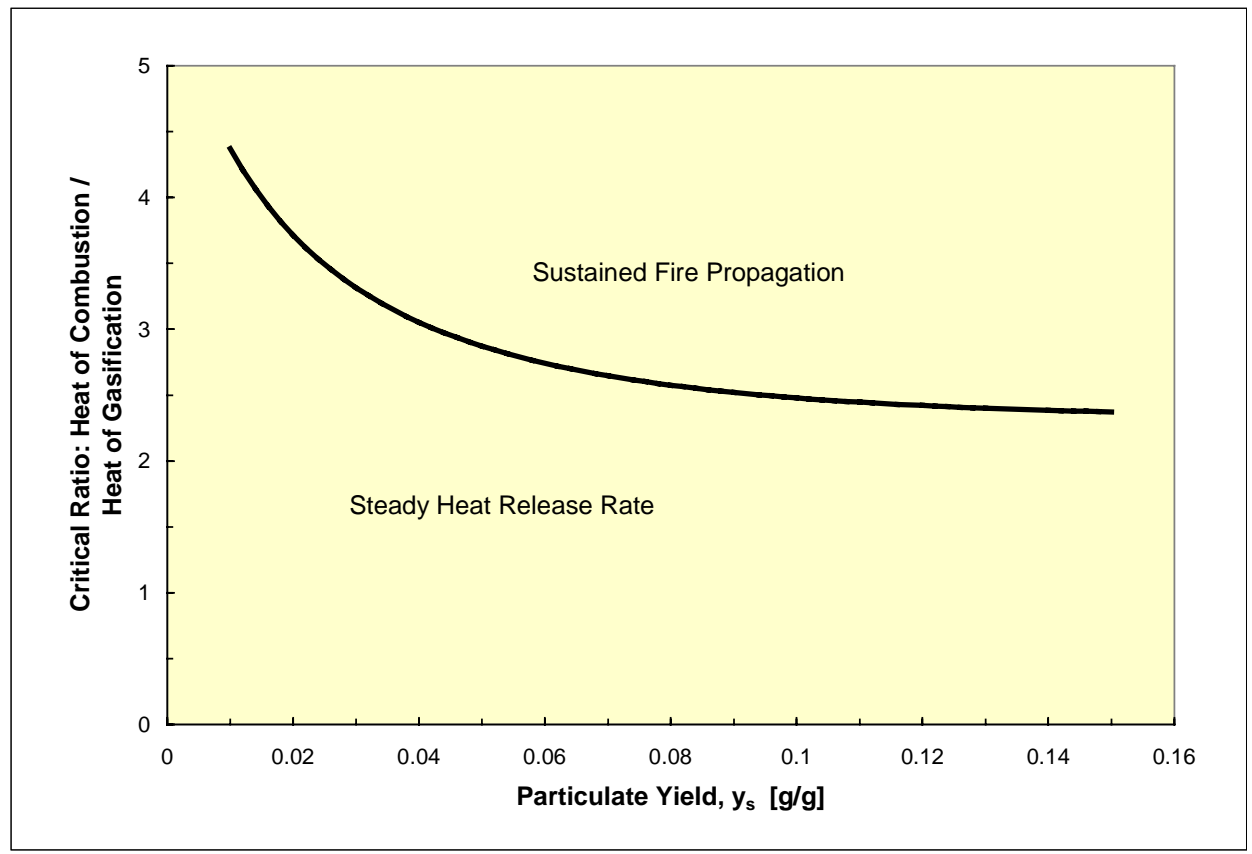

Fig. 2 Critical Conditions for Sustained Fire Propagation Based on Eq. 9 


\section{LABORATORY METHODS}

Equation 8, the simplified model for predicting fire propagation in the parallel panel apparatus, requires just two input parameters, $\Gamma$, the ratio of the heat of combustion to the heat of gasification of a panel specimen, and the particulate yield, $\mathrm{y}_{\mathrm{s}}$. Although Tewarson [19] has previously used a method to obtain the $\Gamma$ ratio from heat release rate as a function of the externally applied heat flux in a laboratory apparatus, the method involves a number of restrictive requirements. A more general technique is to measure separately the two components of $\Gamma$, heat of combustion and heat of gasification.

The heat of combustion, $\Delta H_{c}$, used here is an average derived from the accumulated chemical heat release divided by the mass loss, $\Delta m_{\text {loss }}$ during the period of active flaming, $t_{1}$ to $t_{2}$, in the laboratory Fire Propagation Apparatus (FPA) [20], or,

$$
\Delta H_{c}=\frac{\int_{t_{1}}^{t_{2}} \dot{Q} d t}{\Delta m_{\text {loss }}}[\mathrm{kJ} / \mathrm{g}]
$$

In Eq. 10, the heat release rate is obtained from:

$$
\dot{Q}=1.33 \times 10^{4}\left(\dot{G}_{\mathrm{CO}_{2}}-\dot{G}_{\mathrm{CO}_{2}}^{0}\right)+1.11 \times 10^{4}\left(\dot{G}_{\mathrm{CO}}-\dot{G}_{\mathrm{CO}}^{0}\right)
$$

where $\dot{G}_{\mathrm{CO}_{2}}$ and $\dot{G}_{\mathrm{CO}}[\mathrm{kg} / \mathrm{s}]$ are the generation rates of $\mathrm{CO}_{2}$ and of $\mathrm{CO}$, respectively ( $\dot{G}_{\mathrm{CO}_{2}}^{0}$ and $\dot{G}_{\mathrm{CO}}^{0}$ are values prior to ignition). The coefficients in Eq. 11 represent average values [19] for the polymers being examined in this study.

A method for obtaining heat of gasification, $\Delta H_{g}$, is chosen which requires the least number of assumptions, namely the measurement of fuel mass flux in response to a range of externally applied heat fluxes when there is no flaming combustion. Such measurements are made conveniently in the FPA by using an inflow of $100 \%$ nitrogen. For materials that exhibit thermally thick behavior and do not produce a significant char layer during pyrolysis in a nitrogen environment, there may be a steady-state period of nearly constant fuel mass flux. This fuel mass flux, $\dot{m}^{\prime \prime}$, is related to the externally applied heat flux, $\dot{q}_{e x t}^{\prime \prime}$, in a laboratory apparatus and the radiant heat loss, $\dot{q}_{o}^{\prime \prime}$ from the fuel surface by the following approximate relation:

$$
\dot{m}^{\prime \prime}=\frac{\dot{q}_{e x t}^{\prime \prime}-\dot{q}_{o}^{\prime \prime}}{\Delta H_{g}}=\left(\frac{1}{\Delta H_{g}}\right) \dot{q}_{e x t}^{\prime \prime}-\frac{\dot{q}_{o}^{\prime \prime}}{\Delta H_{g}}
$$


When steady state fuel mass flux is linearly dependent on the externally applied heat flux, the heat of gasification can be obtained simply as the inverse slope of the linear fit [21]. However, when fuel mass flux exhibits transient behavior or when mass flux is not linearly dependent on external flux, an averaging process may be necessary to derive a single heat of gasification value for use in modeling.

The particulate yield input parameter, $\mathrm{y}_{\mathrm{s}}$, used to obtain the correlation in Eq. 5 is an average value defined [22] as follows from optical measurements of $0.6328 \mu \mathrm{m}$ red light extinction in the test section duct of the FPA:

$$
y_{s}=\frac{\int_{t_{1}}^{t_{2}} \dot{G}_{s} d t}{\Delta m_{\text {loss }}}=\frac{\int_{t_{1}}^{t_{2}} 0.0994 \dot{\mathrm{V}} \frac{\ln \left\{I_{a} / I\right\}}{\ell} d t}{\Delta m_{\text {loss }}}
$$

where $\dot{G}_{s}[\mathrm{~g} / \mathrm{s}]$ is the mass flow rate of particulate in the duct, obtained from the optical extinction measurement, $\mathrm{I}_{\mathrm{a}} / \mathrm{I}$ is the inverse fraction of light transmitted over the optical path length, $\ell[\mathrm{m}]$, across the duct, $\dot{V}$ is the volumetric flow rate $\left[\mathrm{m}^{3} / \mathrm{s}\right]$ in the duct test section and $\Delta m_{\text {loss }}[\mathrm{g}]$ is the change in specimen mass during the identical integration period, $\mathrm{t}_{1}$ to $\mathrm{t}_{2}$, used in Eq. 10. Note that $y_{s}$ is proportional to the commonly measured average specific extinction area, the proportionality constant being about 0.0994 when the specific extinction area is in $\left[\mathrm{m}^{2} / \mathrm{g}\right]$.

Laboratory tests in the FPA [20] are performed with commercial materials that represent highly complex pyrolysis behavior. Heat of gasification is determined from tests with external heat fluxes from 15 to $60 \mathrm{~kW} / \mathrm{m}^{2}$ and a $0.08 \mathrm{~m} / \mathrm{s}$ flow of pure nitrogen in the quartz pipe that surrounds the $0.007 \mathrm{~m}^{2}$ diameter specimen. An external flux of 50 $\mathrm{kW} / \mathrm{m}^{2}$ with a $0.16 \mathrm{~m} / \mathrm{s}$ inflow of normal air is used to determine heat of combustion and particulate yield. Material specimens are contained in the "sample holder" described by de Ris and Khan [23], to insure that the specimens are well insulated.

\section{MODEL INPUT PARAMETERS}

The methods described in the preceding section have been applied to three rigid polymer slabs that exhibit steady state burning and pyrolysis behavior in the laboratory FPA. Two of these polymers, one 25.4-mm thick (designation PVC\#1061) and a second 11.9-mm thick (designation PVC \#680), are rigid polyvinylchoride-based, nominally of the same composition (same vendor catalogue information). A third polymer (designation PP \#631) is a 12.5-mm thick fire retarded polypropylene. The top surface of the PVC specimens is coated with about $130 \mathrm{~g} / \mathrm{m}^{2}$ of powdered carbon to insure more complete absorption of thermal radiation in the FPA by the specimen surface. The PP \#631 specimens, tested at an earlier date, have a coating of high temperature black paint. 
Laboratory measurements of heat release rate and particulate generation rate (from Eq. 13) for the three polymer specimens are shown in Fig. 3 and Fig. 4, respectively. Fig. 3 indicates that there are extended periods of steady burning at heat release rates from 100 to $130 \mathrm{~kW} / \mathrm{m}^{2}$ for all three polymers, with no clear distinction among the polymers with respect to this parameter. These steady heat release rate periods occur despite the fact that all three polymers burn non-uniformly with respect to the location of flames on the surface of the specimen and produce an expanding char layer with large fissures. Note that these heat release rates are characteristic of typical fire resistant, low-hazard materials exposed to a $50 \mathrm{~kW} / \mathrm{m}^{2}$ heat flux in a laboratory apparatus.

In Fig. 4, it is seen that there is a distinctly lower particulate generation rate for polymer \#631, compared to the other two. Both the heat of combustion and the particulate yield parameters are calculated from the information in these figures plus measurements of fuel mass loss during the test.

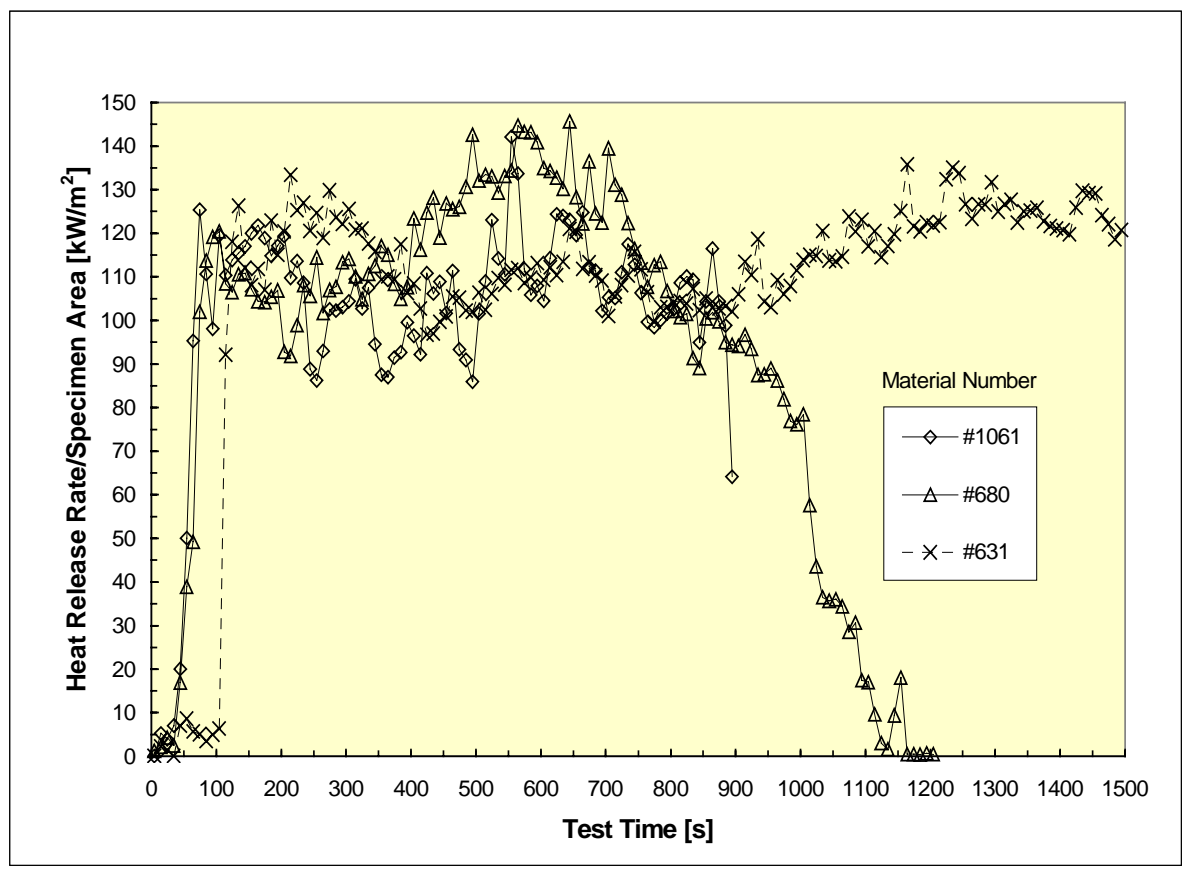

Fig. 3 Heat Release Rate Measurements in the FPA: External Heat Flux of $50 \mathrm{~kW} / \mathrm{m}^{2}$ 


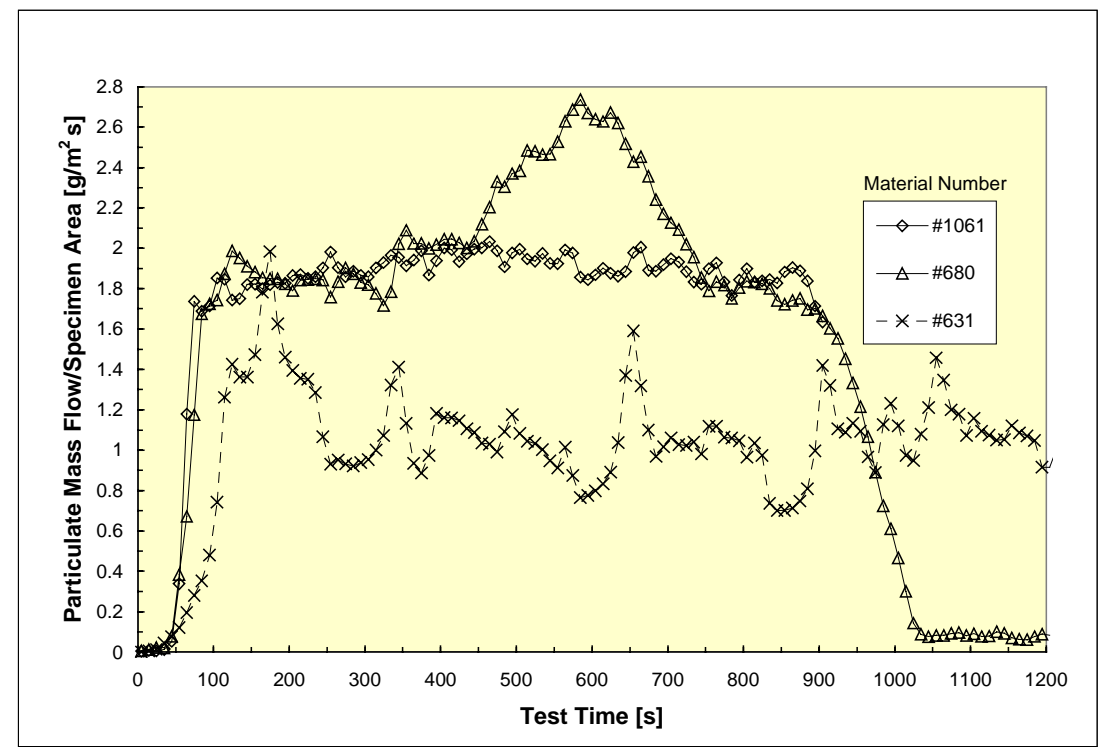

Fig. 4 Particulate Generation Rate Inferred from Optical Extinction: External Heat Flux of $50 \mathrm{~kW} / \mathrm{m}^{2}$

Laboratory measurements of pyrolysis rate in nitrogen are obtained for the three polymers. Mass flux data during pyrolysis of PVC \#1061 are shown in Fig. 5, where extended periods of steady state pyrolysis are observed for each external heat flux in the FPA from 15 to $60 \mathrm{~kW} / \mathrm{m}^{2}$. Note that for these tests, $19-\mathrm{mm}$ thick specimens are cut from the 25.4-mm thick PVC \#1061 sample to stay within the capacity of the load cell.

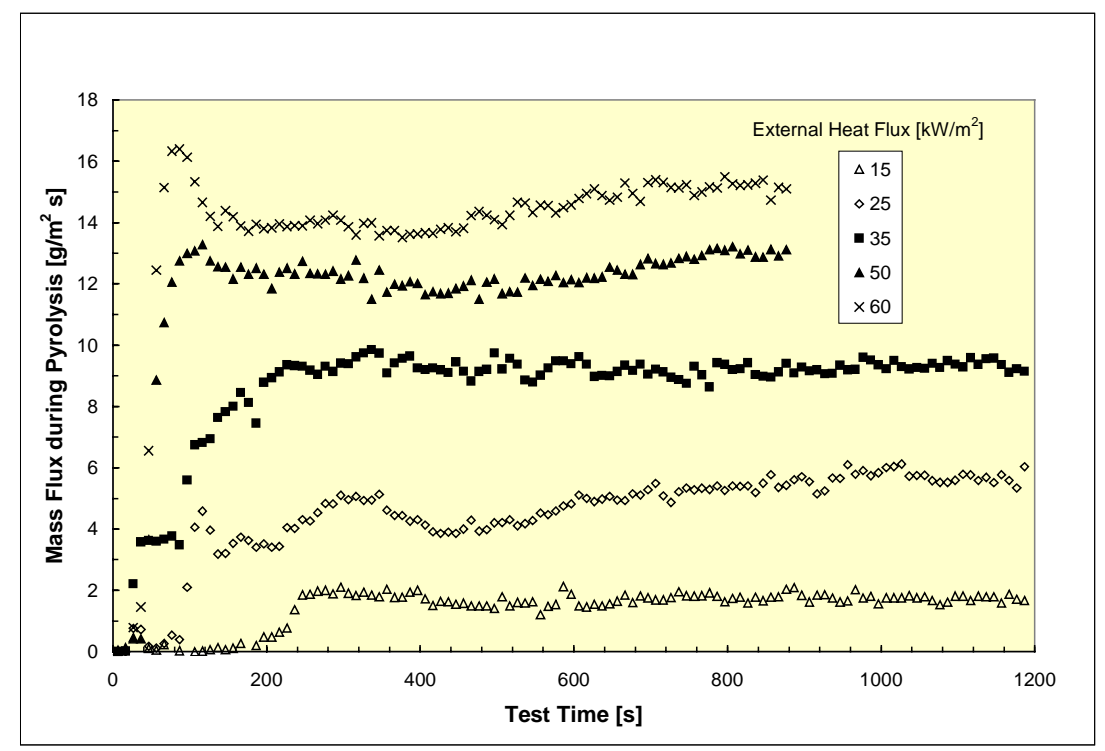

Fig. 5 FPA Pyrolysis Data for PVC \#1061 
From the data for PVC \#1061 in Fig. 5, average values of mass flux corresponding to the entire test duration are used to determine a heat of gasification. For the other two polymers, periods of relatively constant fuel mass flux occur for much shorter periods, typically lasting about $200 \mathrm{~s}$. In this case, steady mass fluxes corresponding to specific 200 -s laboratory test-time internals are analyzed separately.

Plots of selected steady-state pyrolysis data are shown in Fig. 6, along with linear regression fits. Following Eq. 12, heats of gasification can be identified with the inverse of the slopes in this figure. For PVC \#680, the heat of gasification obtained from the 200 to $400 \mathrm{~s}$ interval is about $20 \%$ greater than that obtained at longer pyrolysis test times. However, the earlier pyrolysis behavior is felt to be more critical in determining fire behavior in the parallel panel apparatus, based on previous test observations.

For PP \#631, the heat of gasification obtained from the 200 to $400 \mathrm{~s}$ interval is from 20 to $40 \%$ less than that obtained at longer pyrolysis test times. In this case, use of the 200 to $400 \mathrm{~s}$ interval is more conservative, since the largest possible value of $\Gamma$ is derived.

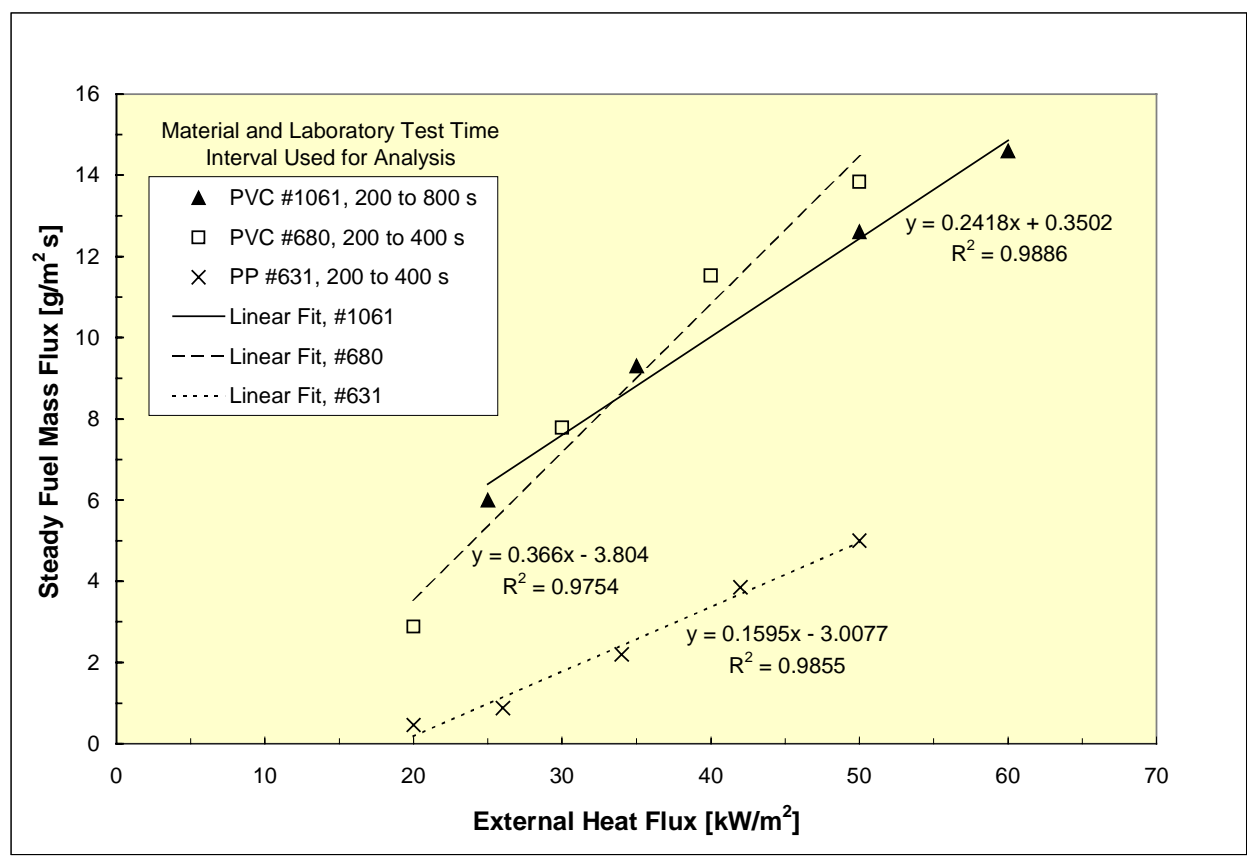

Fig. 6 Heat of Gasification from Slope of Mass Flux vs. External Heat Flux 
Based on the laboratory test data discussed above, the required input parameters for the model are calculated. These parameters are summarized in Table 2. For the range of particulate yields shown in the table, the predicted critical value of $\Gamma$ from Fig. 2 is about 2.4, which means that the PP \#631 should exhibit sustained fire propagation and the PVC \#1061 should exhibit a steady-state heat release rate. The third polymer, PVC \#680 with $\Gamma$ of 2.8 , may be sufficiently close to the critical condition to exhibit an intermediate type of behavior.

Table 2 Inputs for Modeling Fire Behavior in the Parallel Panel Apparatus

\begin{tabular}{|c|c|c|c|c|}
\hline $\begin{array}{c}\text { Material } \\
\text { No. }\end{array}$ & $\begin{array}{c}\text { Heat of } \\
\text { Combustion } \\
{[\mathrm{kJ} / \mathrm{g}]}\end{array}$ & $\begin{array}{c}\text { Heat of } \\
\text { Gasification } \\
{[\mathrm{kJ} / \mathrm{g}]}\end{array}$ & $\begin{array}{c}\Gamma \text { Ratio } \\
{[-]}\end{array}$ & $\begin{array}{c}\text { Particulate } \\
\text { Yield } \\
{[\mathrm{g} / \mathrm{g}]}\end{array}$ \\
\hline 1061 & 6.96 & 4.1 & 1.7 & 0.122 \\
\hline 680 & 7.57 & 2.7 & 2.8 & 0.130 \\
\hline 631 & 20.0 & 6.3 & 3.2 & 0.107 \\
\hline
\end{tabular}

\section{COMPARISON WITH BEHAVIOR IN THE PARALLEL PANEL APPARATUS}

The Parallel Panel apparatus rigidly clamps two 0.6-m wide and 2.44-m high panels to a $0.3-\mathrm{m} \times 0.6-\mathrm{m}$ sand burner such that the bottom edge of each panel is in contact with the 0.6-m-wide top edge of the burner. A panel consists of the test specimen, backed by a 25-mm thick sheet of calcium silicate board, which, in turn, is backed by a 13-mm thick sheet of plywood (see Fig. 1). The flow rate of chemically pure (CP-grade) propane to the sand burner is measured with a calibrated rotometer. Typically at FM Global Research, a nominal burner heat release rate of $60 \mathrm{~kW}$, corresponding to a $0.61-\mathrm{m}$ flame height, is used to evaluate panel specimens. However, in this study, results corresponding to burner heat release rates from 15 up to $100 \mathrm{~kW}$ are analyzed.

Tests are initiated by igniting the propane sand burner (defined as a Test Time of zero) while protecting the panel specimens from the burner flame for a minute or more. This is achieved by covering the lower portion of the panel specimens with inert insulation boards until a steady heat release rate is measured in the instrumented collection duct. In this way, errors caused by thermal transients in the burner or by improper operation of the gas analysis instruments can be evaluated in the absence of panel combustion. Once a steady-state measurement is achieved, the insulation boards are removed rapidly (within about 5 or 10 seconds) and specimen exposure begins.

Heat release rates from tests at various burner intensities in the parallel panel apparatus are shown in Fig. 7, Fig. 8 and Fig. 9 for the three panel materials. For PVC \#1061, Fig. 7 shows that steady burning behavior in the apparatus is achieved with all three propaneburner heat release rates. At the $95 \mathrm{~kW}$ burner intensity, average flame height is at the top of the panel but the pyrolysis front is still 122-mm below the top of the panel (pyrolysis height of $2.3 \mathrm{~m}$ ) at the end of the 20-minute exposure duration. With the 55 and $75 \mathrm{~kW}$ burner exposures, the maximum pyrolysis front height is $1.4 \mathrm{~m}$ and $1.8 \mathrm{~m}$, respectively. 
For PVC \#680, Fig. 8 shows that fire heat release rate becomes steady for the $55 \mathrm{~kW}$ burner intensity, with a maximum pyrolysis height in the apparatus of $1.3 \mathrm{~m}$. However, a rapid increase in parallel panel heat release rate occurs at test times of 570 and $470 \mathrm{~s}$ for the 78 and $102 \mathrm{~kW}$ burner intensities, respectively. The rapid increases in heat release rate coincide with upward fire propagation until average flame heights are well above the top of the panels and pyrolysis heights are $2.2 \mathrm{~m}$ and $2.4 \mathrm{~m}$, respectively. At this point, flames are extinguished quickly by hand-held hose streams, which is the reason that heat release rates drop quickly back toward zero.

For PP \#631, Fig. 9 shows that fire heat release rate becomes steady for the $15 \mathrm{~kW}$ burner intensity, with a maximum pyrolysis height in the apparatus of $0.4 \mathrm{~m}$. However, a rapid increase in parallel panel heat release rate occurs for an increase in burner intensity to 25 $\mathrm{kW}$. As for PVC \#680, this increase in heat release rate, up to a peak measured value of nearly 1 MW (not shown in Fig. 9), coincides with rapid upward fire propagation to the top of the panel.

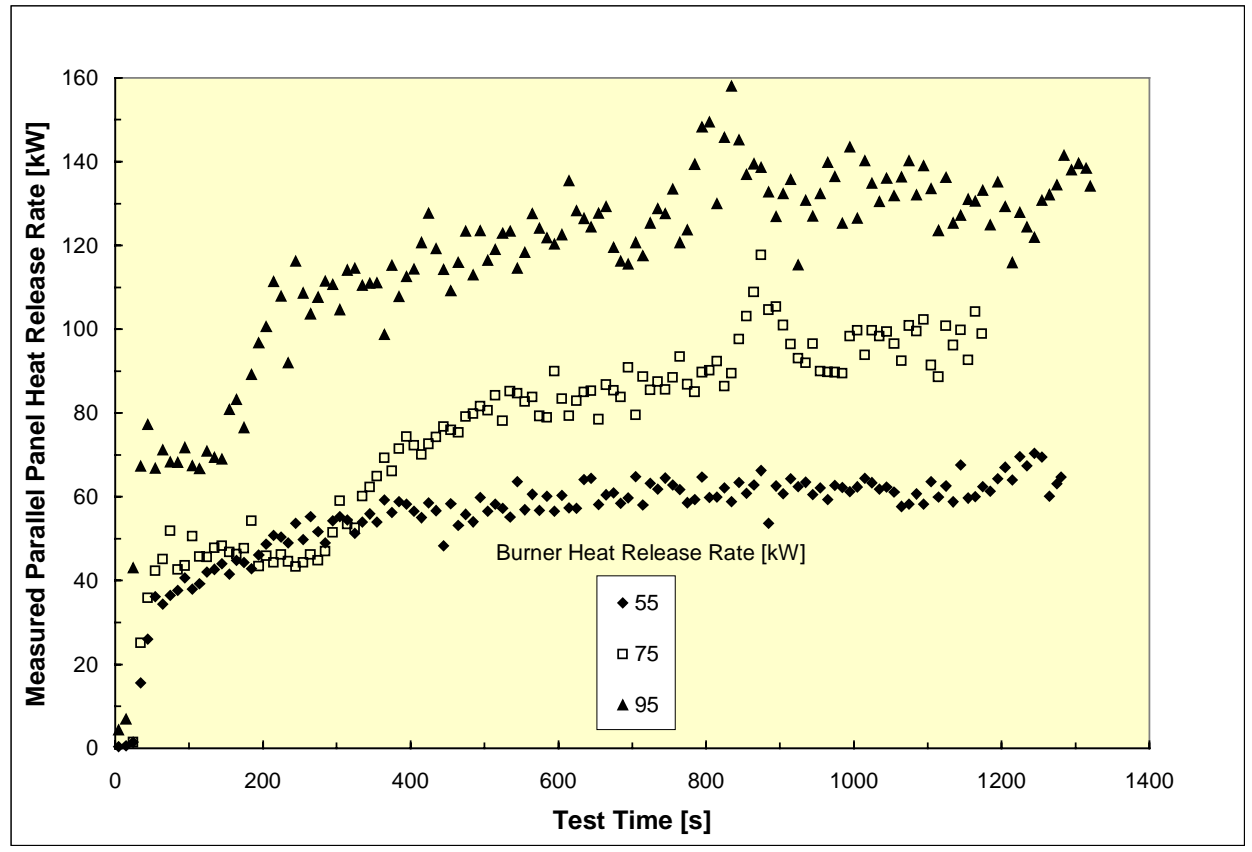

Fig. 7 Heat Release Rate of Parallel, PVC \#1061 Panels 


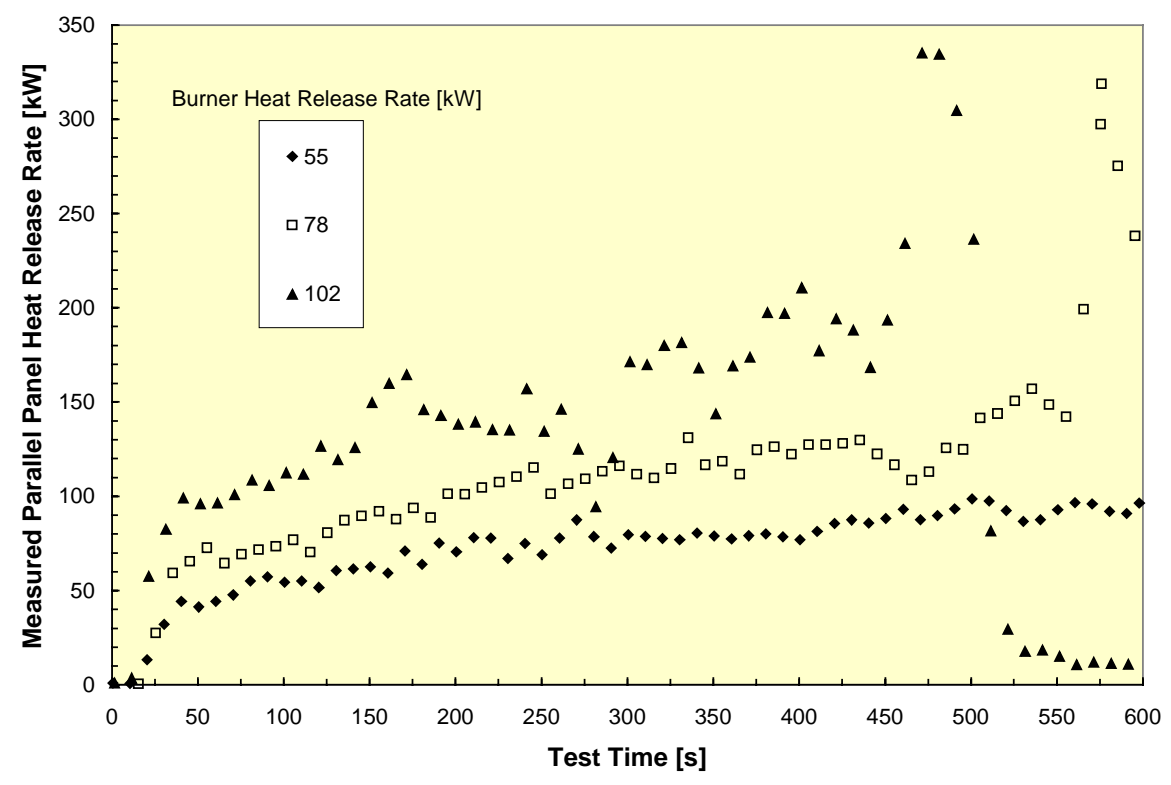

Fig. 8 Heat Release Rate of Parallel, PVC \#680 Panels

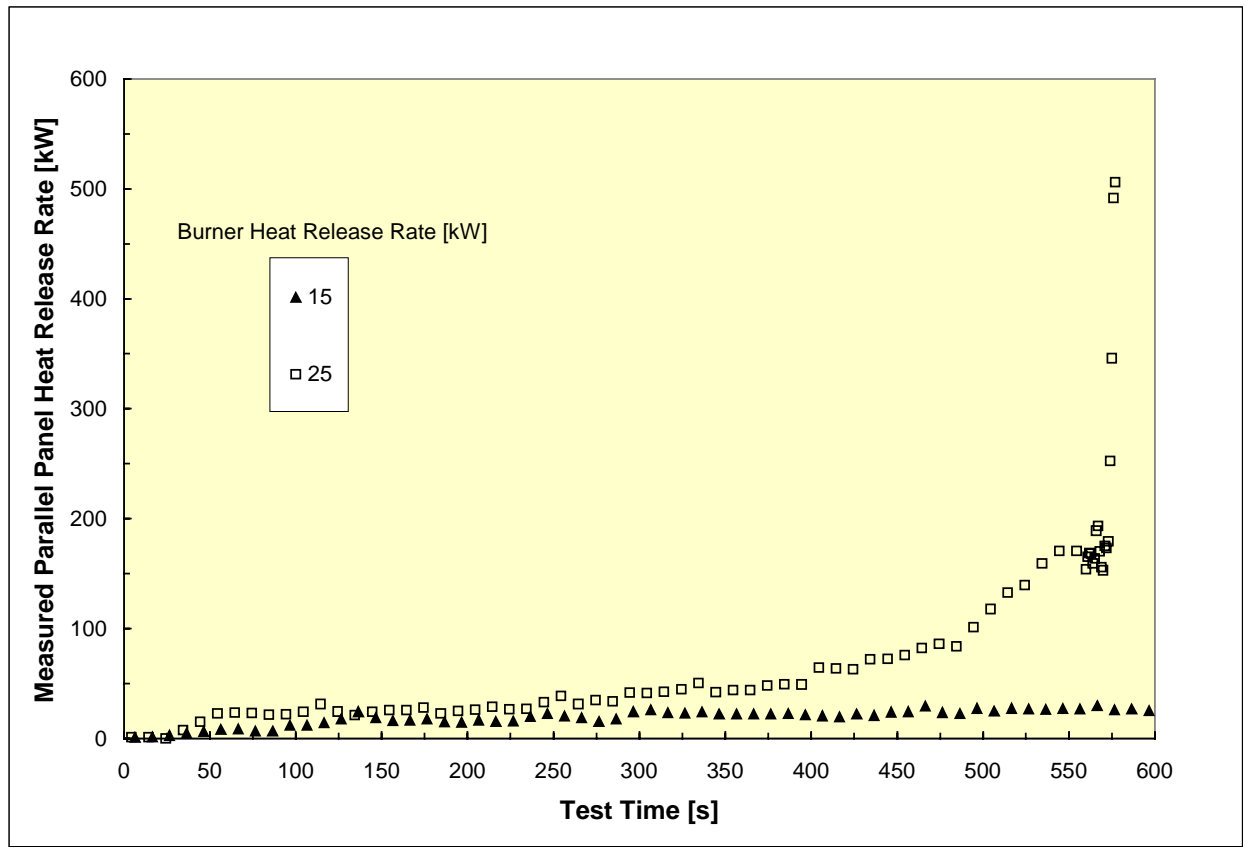

Fig. 9 Heat Release Rate of Parallel, PP \#631 Panels 
Results of testing the three polymers in the parallel panel apparatus are summarized in Table 3. Here, the heat release rates that are predicted from Eq. 8 are seen to be 2 to 3 times the values that are measured for the steady burning periods of PVC \#1061. However, the model correctly predicts steady burning for PVC \#1061 and the sustained fire propagation seen with the other two polymers. Obviously, the flame heat transfer expression in this version of the model is only a rough approximation of the actual heat transfer processes in the specific parallel panel configuration that has been tested. More accurate knowledge of flame heat transfer would be expected to improve the prediction of heat release rates and show how the intensity of the burner exposure affects fire behavior.

In the last column of Table 3 is an approximate calculation of average heat flux from flames in the parallel panel. As noted previously, the net flame heat transfer to the panel specimens is assumed to be the total radiant emission given by Eq. 6. To evaluate Eq. 6, the measured heat release rate (third column of Table 3 ) is substituted for $\dot{Q}_{T}$. If this flame heat transfer from Eq. 6 is then divided by the total area of the panels up to the measured pyrolysis height, an average flame heat flux results. The resultant calculated flux is seen to be $26 \mathrm{~kW} / \mathrm{m}^{2}$ or less for the five tests in which there is steady burning and greater than $48 \mathrm{~kW} / \mathrm{m}^{2}$ for the three tests in which sustained fire propagation occurs.

Table 3 Summary of Parallel Panel Test Results

\begin{tabular}{|c|c|c|c|c|}
\hline $\begin{array}{c}\text { Material } \\
\text { Number }\end{array}$ & $\begin{array}{c}\text { Heat Release } \\
\text { Rate of Propane } \\
\text { Burner } \\
{[\mathrm{kW}]}\end{array}$ & $\begin{array}{c}\text { Measured } \\
\text { Steady Heat } \\
\text { Release Rate } \\
{[\mathrm{kW}]}\end{array}$ & $\begin{array}{c}\text { Heat Release } \\
\text { Rate from Eq. 8 }\end{array}$ & $\begin{array}{c}\text { Net Heat Flux to } \\
\text { Panels from } \\
\text { Eq. 6 } \\
{[\mathrm{kW}]}\end{array}$ \\
\hline 1061 & 55 & 63 & 185 & 16 \\
\hline 1061 & 75 & 96 & 252 & 18 \\
\hline 1061 & 95 & 137 & 320 & 20 \\
\hline 680 & 55 & 98 & $*$ & $>49$ \\
\hline 680 & 78 & $\left.>320^{2}\right]$ & $>48$ \\
\hline 680 & 102 & $>334^{*}$ & $*$ & 22 \\
\hline 631 & 15 & 26 & $*$ & $>133$ \\
\hline 631 & 25 & $>975^{*}$ & $*$ & 26 \\
\hline
\end{tabular}

*Sustained fire propagation is observed or predicted

\section{CONCLUSIONS}

The intermediate-scale, parallel panel apparatus is coupled with a model based on global energy conservation to determine whether three polymer materials will support unlimited fire propagation. Use of the model allows two parameters controlling fire propagation tendency in the apparatus, the ratio of heat of combustion to heat of gasification and the particulate yield, to be identified. The heat of gasification is a key input that can best be determined from laboratory tests in a $100 \%$ nitrogen environment, which allow pyrolysis behavior to be measured while eliminating ambiguities introduced by heat transfer from the specimen flame itself. 


\section{ACKNOWLEDGEMENTS}

The author is indebted to the following staff members of FM Global Research: Dr. John L. de Ris for discussions that led to the modeling approach taken in this paper; Dr. Peter $\mathrm{K}$. Wu, who initiated all testing with PP \#631 and parallel panel tests with PVC \#680 as part of a separate study; Mr. Lawrence Orloff, who designed the parallel panel tests with PVC \#1061; and Mr. Stephen D. Ogden, who performed the laboratory FPA tests. The author thanks the staff of the FM Global Technology Center for performing the parallel panel tests. This work is part of the Flammability Technology Research Program supported by FM Global.

\section{REFERENCES}

[1] Hasemi, Y., "Thermal Modeling of Upward Wall Flame Spread," Fire Safety Science - Proceedings of the First International Symposium, Hemisphere Publishing Corporation, Washington, 1986, pp. 87-96.

[2] Delichatsios, M.M., Mathews, M.K. and Delichatsios, M.A., "Upward Flame Spread and Growth Simulation," Fire Safety Science - Proceedings of the Third International Symposium, Elsevier Science Publishers, LTD, Essex, England, 1991, pp. 207-216.

[3] Karlsson, B., "Models for Calculating Flame Spread on Wall Lining Materials and the Resulting Heat Release Rate in a Room," Fire Safety Journal 23: 365-386 (1994).

[4] Karlsson, B., "Mathematical Models for Calculating Heat Release Rate in the Room Corner Test," Fire and Flammability of Furnishings and Contents of Buildings, ASTM STP 1233, Fowell, A.J. (ed.), The American Society for Testing and Materials, West Conshohocken, PA, USA, 1994, pp. 216-236.

[5] Mitler, H.E., "Predicting the Spread Rates of Fires on Vertical Surfaces," TwentyThird International Symposium on Combustion, The Combustion Institute, Pittsburgh, PA, USA, 1990, pp. 1715-1721.

[6] Kulkarni, A., Kim, C. and Kuo, C., "Turbulent Upward Flame Spread for Burning Vertical Walls Made of Finite Thickness,", National Institute of Standards and Technology, Report NIST-GCR-91-597, Gaithersburg, MD, USA, 1991.

[7] Kokkala, M.A., Thomas, P.H. and Karlsson, B., "Rate of Heat Release and Ignitability Indices for Surface Linings,” Fire and Materials 17: 209-216 (1993).

[8] Quintiere, J.G., "A Simulation Model for Fire Growth on Materials Subject to a Room-Corner Test," Fire Safety Journal 20: 313-339 (1993).

[9] Quintiere, J.G., Haynes, G. and Rhodes, B.T., "Applications of a Model to Predict Flame Spread over Interior Finish Materials in a Compartment," Journal of Fire Protection Engineering 7,1: 1-13 (1995).

[10] Kokkala, M., Baroudi, D. and Parker, W.J., "Upward Flame Spread on Wooden Surface Products: Experiments and Numerical Modeling," Fire Safety Science Proceedings of the Fifth International Symposium, International Association for Fire Safety Science, 1997, pp. 309-320.

[11] Williams, F.W., Beyler, C.L., Hunt, S.P. and Iqbal, N., "Upward Flame Spread on Vertical Surfaces," Naval Research Laboratory, Report NRL/MR/6180-97-7908, Washington, DC, USA 1997. 
[12] Yan, Z. and Holmstedt, G., "CFD Simulation of Upward Flame Spread over Fuel Surface," Fire Safety Science - Proceedings of the Fifth International Symposium, International Association for Fire Safety Science, 1997, pp. 345-356.

[13] Jia, F., Galea, E.R. and Patel, M.K., "The Numerical Simulation of Enclosure Fires Using a CFD Fire Field Model Coupled with a Pyrolysis Based Solid Fuel Combustion Submodel - A First Approximation," Journal of Fire Protection Engineering 9,4: 1-17 (1999).

[14] Lattimer, B.Y., Hunt, S.P., Sorathia, U., Blum, M., Gracik, T., McFarland, M., Le, A. and Long, G., "Development of a Model for Predicting Fire Growth in a Combustible Corner,” Naval Surface Warfare Center, Report NSWCCD-TR-64-1999/07, Carderock Division, West Bethesda, MD 20817-5700, USA 1999.

[15] Wang, H.Y., Joulain, P.and Most, J.M., "Modeling on Burning of Large-Scale Vertical Parallel Surfaces with Fire-Induced Flow," Fire Safety Journal 32: 241-271 (1999).

[16] Brehob, E.G., Kim, C.I. and Kulkarni, A.K., "Numerical Model of Upward Flame Spread on Practical Wall Materials," Fire Safety Journal 36: 225-240 (2001).

[17] Wu, P.K., "Parallel Panel Fire Tests for Flammability Assessment," $8^{\text {th }}$ International Fire Science and Engineering Conference (Interflam'99), Interscience Communications, London, 1999, pp. 605-614.

[18] Markstein, G.H., "Relationship between Smoke Point and Radiant Emission from Buoyant Turbulent and Laminar Diffusion Flames," Twentieth Symposium (International) on Combustion, The Combustion Institute, Pittsburgh, PA, USA, 1984, pp. 1055-1061.

[19] Tewarson, A., "Generation of Heat and Chemical Compounds in Fires," The SFPE Handbook of Fire Protection Engineering ( $3^{\text {rd }}$ ed), DiNenno P.J. (ed), National Fire Protection Association, Quincy, MA, 02269, USA, 2002, pp. 3-131 to 3-137.

[20] ASTM E 2058, "Standard Test Methods for Measurement of Synthetic Polymer Material Flammability Using a Fire Propagation Apparatus (FPA)," Annual Book of ASTM Standards, Vol. 4.07, American Society for Testing and Materials, West Conshohocken, PA, USA, 2001.

[21] Tewarson, A. and Pion, R.F., "Flammability of Plastics: I. Burning Intensity," Combustion and Flame 26: 85-103 (1976).

[22] Newman, J.S. and Steciak, J., "Characterization of Particulates from Diffusion Flames," Combustion and Flame 82: 211-230 (1990).

[23] de Ris, J.L. and Khan, M.M., "A Sample Holder for Determining Material Properties," Fire and Materials 24: 219-226 (2000). 